\title{
A semi-quantitative assay of overall DNA methylation status using Methyl-CpG binding protein (MBD1)
}

\author{
Chunxiao Zhang, Runsheng Li and Ruqian Zhao*
}

\begin{abstract}
Background: In mammals, DNA methylation at the 5-position of cytosine is the most essential epigenetic modification. Changes in the level of genome-wide DNA methylation (also known as overall DNA methylation) are associated with alterations in gene expression, thereby contributing to the phenotypic and physiological diversity. Current technologies for detecting overall DNA methylation either suffer from low sensitivity or require sophisticated equipment. Studies on domestic animals are hampered by the lack of complete and annotated genomic information.

Results: Here we report a rapid slot blot method using methyl-CpG binding protein (MBD1) to exam the level of overall DNA methylation in pigs and chickens. Using this rapid approach, we determined the methylation status in various DNA samples of a Chinese indigenous (Erhualian) and a Western (Large White) breed of pigs. We also chose day 18 embryos (E18) and newly hatched chicks (D1) of a Chinese indigenous chicken breed (Wen's yellowfeathered broiler chicken) for genome-wide DNA methylation analysis. The results revealed tissue- and breedspecific differences, as well as age-dependent variations, in the level of overall DNA methylation.

Conclusion: The results showed that the slot blot assay is a sensitive, highly specific and convenient method for semi-quantitative estimation of overall DNA methylation with no species specificity. This method does not require sophisticated equipment, such as high performance liquid chromatography (HPLC), or expensive technologies like sequencing, thus providing a useful tool for overall DNA methylation studies on domestic animals.
\end{abstract}

Keywords: Overall DNA methylation, MBD1, Slot blot assay

\section{Background}

DNA methylation of the CpG dinucleotide is one of the most crucial epigenetic modifications in mammals [1]. Its feature is a modification of the 5 -position of the pyrimidine ring of cytosine that produces 5-methylcytosine $(5 \mathrm{mc})$. A large body of literature demonstrates that the level of genome-wide DNA methylation (also is referred to as overall DNA methylation) changes dynamically during the course of normal development, and this epigenetic regulation is critical in the determination of cell fate during embryogenesis [2,3]. For example, during the preimplantation stage, the mammalian genome becomes progressively

\footnotetext{
* Correspondence: zhao.ruqian@gmail.com

Key Laboratory of Animal Physiology \& Biochemistry, Nanjing Agricultural University, Nanjing 210095, People's Republic of China
}

demethylated, which is associated with the initiation of cellular differentiation of somatic cells [3].

On the contrary, impairment of methylation can damage assorted aspects of gene regulation, such as X chromosome inactivation [1], genomic imprinting [4] and retroviral silencing [5]. Additionally, environmental factors, such as ionizing radiation [6] and hormone exposure [7], could influence the overall level of DNA methylation, which results in altered molecular pathways and increased risk of diseases. Thus, DNA methylation may help explain the pathophysiology of diseases. Furthermore, the aberrant genome-wide DNA methylation also plays a critical role in tumorigenesis [8]. The overall DNA methylation level in tumor-derived genomic DNA is reported to be significantly reduced. Hypomethylation of overall DNA methylation in tumor tissue has become a common hallmark in a variety of malignancies, such as breast, colon, and blood cancers 
$[9,10]$. Recently, a large number of studies have focused on the methylation status of specific genes to identify the cancer associated changes in DNA methylation at specific loci. However, analysis of genome-wide DNA methylation could provide an overview that may be missed in studies limited to specific genes of interest.

In order to understand the role of overall DNA methylation in development and disease, a wide range of approaches have been developed $[11,12]$. Generally speaking, there are four groups of approaches for detecting the changes of DNA methylation at the genome-scale level. The first group is high-performance separation techniques, such as high performance liquid chromatography (HPLC), HPLCmass spectrometry (HPLC-MS), high performance capillary electrophoresis (HPCE), etc. The separation techniques require expensive and sophisticated equipment and significant experimental experience to obtain reproducible results. In addition, the DNA samples have to be hydrolyzed. The second group is based on enzymatic/chemical approaches such as the methyl-acceptor assay and the chloroacetaldehyde assay. These methods are not as sensitive as the high-performance separation techniques, and sometimes their resolution is limited to endonuclease cleavage sites and incomplete DNA digestion. The third group is bisulfite sequencing, which relies on bisulfite treatment to deaminate the unmethylated cytosine into uracil, thus allowing differentiation of methylated (protected from deamination) and unmethylation cytosine by deep sequencing. Although this technique allows whole genome analysis, it is costly and requires significant bioinformatics expertise and well annotated genomic information of the species. The fourth group is mentioned in literature in which DNA samples are immobilized on membranes and the methylation level is detected by the anti-5mc antibodies. But in order to expose the epitopes, DNA must be denatured into single strand.

The methyl-CpG binding domain (MBD), on the contrary, can detect native double-stranded CpG-methylated DNA [13]. MBD is a family of mammalian proteins whose original function is to recruit transcriptional repression complexes to silence gene expression [14]. MBD1, MBD2, MBD4 and MeCP2 have high affinity to a symmetrically methylated CpG motif [15], and MBD1 binds more efficiently to densely methylated DNA $[16,17]$ with sequence preference in the neighboring nucleotides [18]. Methods using the MBD family protein provide an advantage compared to the previously discussed ones because no pretreatment or conversion of the sample DNA is required. Large numbers of detection protocols have focused on applying the methyl binding proteins to capture the methylated DNA, such as methylated-CpG island recovery assay (MIRA) [19], and MBD-isolated Genome Sequencing (MiGS) [17]. Because high-throughput DNA sequencing is employed, these approaches have extremely high sensitivity and can provide information about DNA methylation for specific DNA loci at a resolution of nearly 50-100 bp. However, high-throughput sequencing is expensive, time consuming and most importantly, depends on substantial species-specific genomic database, which is not always available for domestic animals.

Previous studies used MBD1 protein to determine the methylated lambda phage DNA ( $\lambda \mathrm{DNA})$ with slot blot assay $[20,21]$. Here we extend the application of the assay for detecting the relative percentage of genomic DNA methylation by using the same MBD1 protein. The assay does not require high-performance separation equipment or methylation-sensitive restriction enzymes, yet provides a quick, simple and inexpensive semi-quantitative technique for the detection of methylated DNA. Using this rapid approach, we measured genome-wide DNA methylation levels in different DNA samples of a Chinese indigenous (Erhualian) and a Western (Large White) breed of pigs. Also, we chose day 18 embryo (E18) and newly hatched chicks (D1) of a Chinese indigenous chicken breed (Wen's yellow-feathered broiler chicken) for this methylation level analysis. The semi-quantitative analysis revealed tissueand breed-specific differences, as well as age-dependent variations in the overall DNA methylation level.

\section{Results}

\section{Specificity of the slot blot assay}

As shown in Figure 1a, the specificity of the MBD1 protein was tested against M.SssI-methylated and non-methylated $\lambda$ DNA following the method described previously [20,21]. Serial dilution of methylated $\lambda$ DNA samples demonstrated increasing band intensity, indicating the status of DNA methylation (Figure 1c). The assay demonstrated high specificity, as signals were obtained only in the slots containing the methylated $\lambda \mathrm{DNA}$, which is consistent with previous publications [20,21]. A linear regression analysis showed quantitative recovery across the entire methylation range (0-100\%), with a $\mathrm{R}^{2}$ of 0.9705 (Figure $1 \mathrm{~d}$ ). The blot stained with methylene blue demonstrated equal loading of total DNA on each slot (Figure 1b).

\section{Sensitivity of the slot blot assay}

We examined the sensitivity of methyl-CpG-binding by incubating recombinant MBD1 protein with membranes carrying different quantities of genomic DNA. Genomic DNA extracted from the muscle of D1 chicken was used, and the result suggested that the slot blot routinely allowed detection of genomic DNA to a sensitivity of $0.5 \mu \mathrm{g}$ (Figure 2).

\section{Differences of overall DNA methylation levels among different tissues of two pig breeds}

We utilized the slot blot assay to assess the level of overall DNA methylation among three types of tissues (liver, adrenal gland and psoas muscle) of two breeds of newborn 

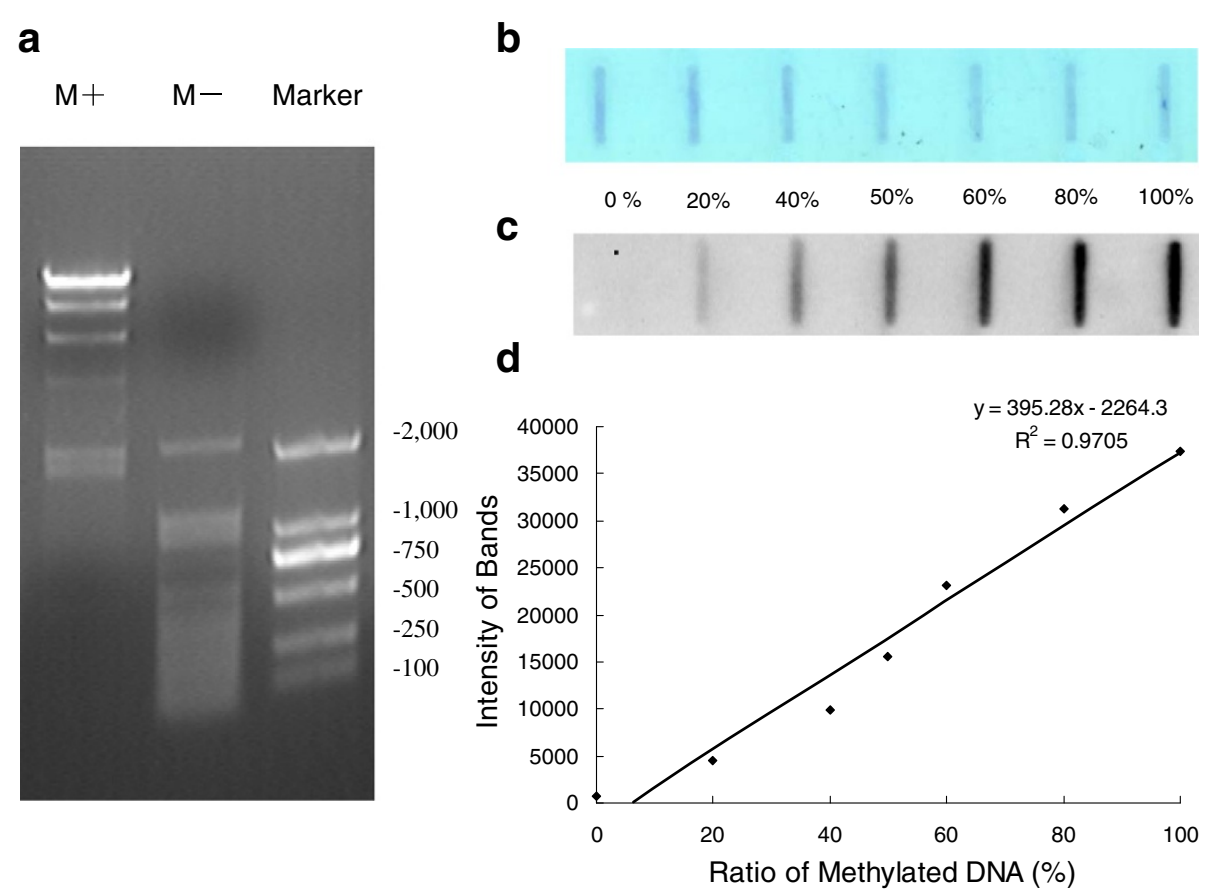

Figure 1 Specificity of the slot blot assay using MBD1 protein. (a) Methylation status of the $\lambda$ DNA assessed by Hpall endonuclease restriction analysis shows that in vitro methylated $\lambda D N A(M+)$ was resistant to endonuclease cleavage, but unmethylated $\lambda$ DNA (M-) was not. (b) Methylated $\lambda D N A(100 \%)$ was added in increasing amounts to unmethylated $\lambda$ DNA (0\%) to create a dilution series of methylated DNA from $0 \%$ to $100 \%$ in a total amount of $500 \mathrm{ng}$. The blot was stained with methylene blue to ensure the equal loading of total DNA. (c) The same blot detected by MBD1. (d) The observed band intensity was plotted against the methylation percentage. The regression equation with an adjusted $R^{2}$ of 0.9705 was presented on figure.

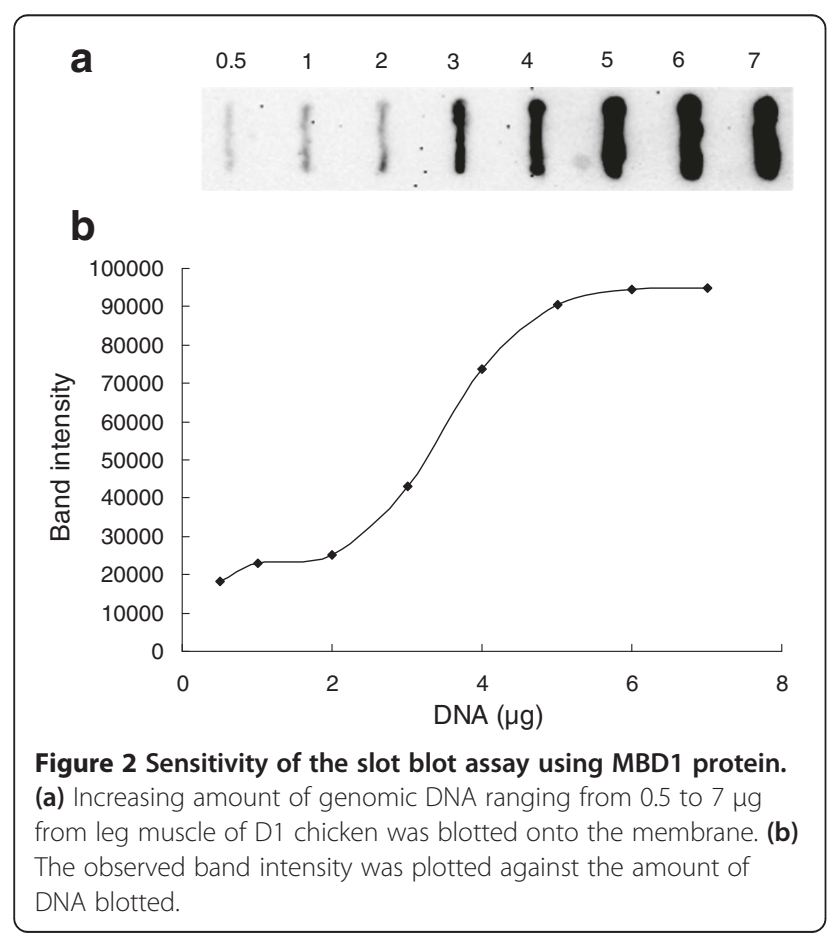

piglets $(n=6)$. Increasing amounts of porcine genomic DNA (a mix of all the samples detected) were blotted onto the membrane (Figure 3a) to plot a standard curve with band intensity against DNA quantity (Figure $3 b$ ). The band intensity is log-linear to the DNA amount (Figure 3c). The result showed that the band intensity from $4 \mu \mathrm{g}$ of DNA is within the linear range of the standard curve. We found that the most highly methylated DNA was from the psoas muscle. The differences between muscle and the other two tissues, liver and adrenal gland, were significant with $\mathrm{p}<0.05$ (Figure 3d). The degree of genomic DNA methylation is higher in Erhualian piglets than in Large White in all the three tissue types, and a significant breed difference was detected in liver $(\mathrm{p}=0.034)$.

\section{Differences of overall DNA methylation levels among different tissues at two developmental stages in the chicken}

The overall DNA methylation levels of chicken liver, kidney, intestine, and leg muscle exhibited a decrease at D1 compared to E18 $(n=6)$. The age-related drop in overall DNA methylation level was significant in kidney $(\mathrm{p}=0.05)$ (Figure 4). At E18, the overall DNA methylation level of kidney is significantly higher than that of liver. But at D1, 


\section{a}

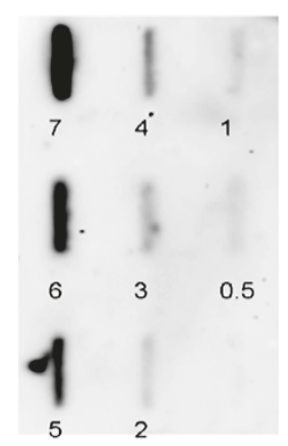

\section{b}

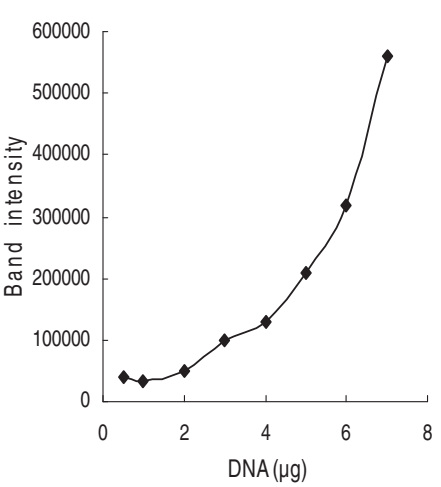

C

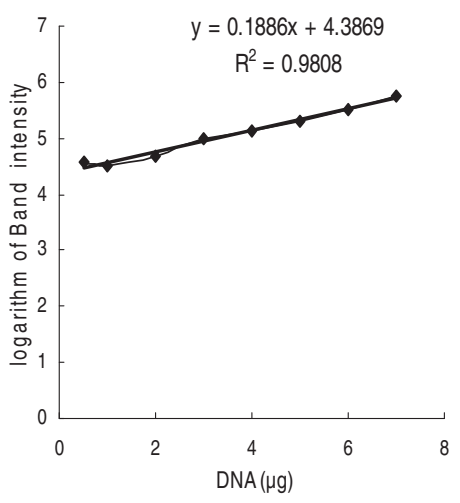

d

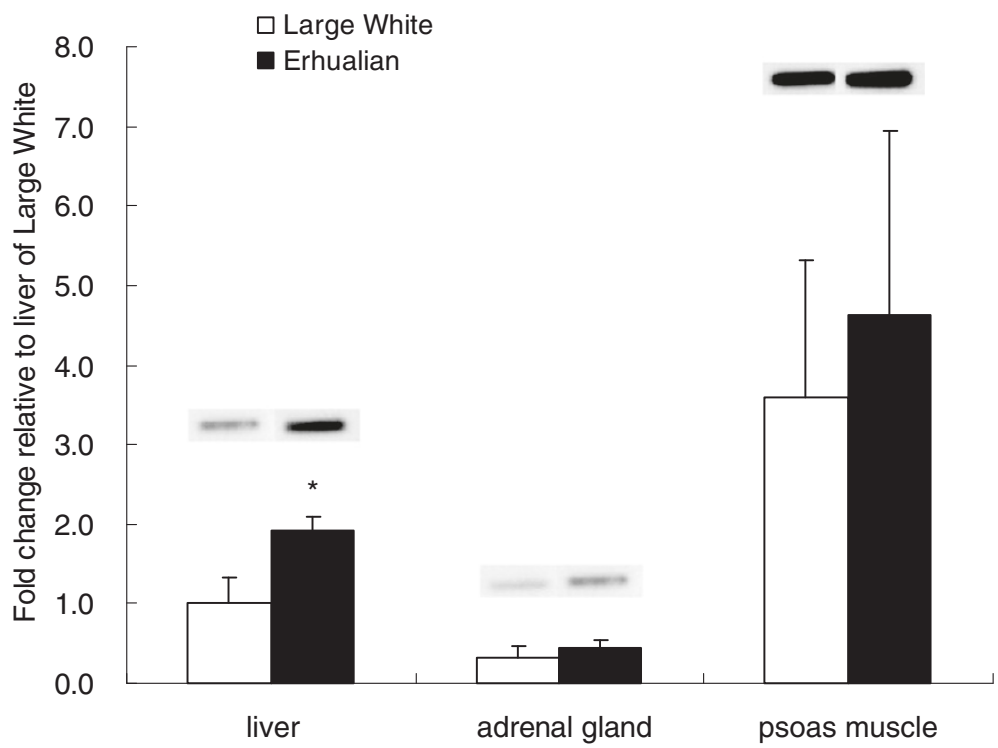

Figure 3 Utilizing the slot blot assay to detect the overall DNA methylation level of newborn piglets. (a) Increasing amount of porcine genomic DNA (a mix of all the samples detected) ranging from 0.5 to $7 \mu \mathrm{g}$ (marked underneath each band) was blotted onto the membrane. (b) The observed band intensity was plotted against the amount of DNA blotted. (c) The logarithm of band intensity was plotted against the amount of DNA blotted. (d) $4 \mu \mathrm{g}$ of genomic DNA from three types of tissues of male Large White and Erhualian piglets was used $(n=6)$. Data are presented as means $\pm S E$. ${ }^{*}$ means significant difference between pig breed $(p<0.05)$.

the DNA methylation level did not exhibit significant difference among the tissues.

\section{Verification by using anti-5mc antibody}

To confirm our slot blot assay, we compared two of the results with conventional Southern blotting with commercial anti-5mc antibody. We chose the DNA samples of the liver of two pig breeds, and D1 chicken tissues as examples. Genomic DNAs were denatured in a $95^{\circ} \mathrm{C}$ water bath and put on ice immediately. Then they were immobilized on nitrocellulose membranes and detected with commercial anti-5mc antibody (1:5000) followed by HRP-anti-mouse antibody. The pattern of overall DNA methylation in different tissues was consistent with that detected by our method (Figure 5a, b).

\section{Discussion}

In this study, we demonstrated the feasibility of immobilizing genomic DNA on membranes with slot blotting followed by interaction with MBD1 protein for quantifying overall DNA methylation. Most of the currently available methods require DNA to be denatured by heating in order to fully expose the epitopes [22,23]. The assay developed in this study can avoid subjecting the specimen to rough denaturing conditions, as MBD1 could recognize $5 \mathrm{mc}$ in duplex DNA. The sensitivity of this assay is similar to 

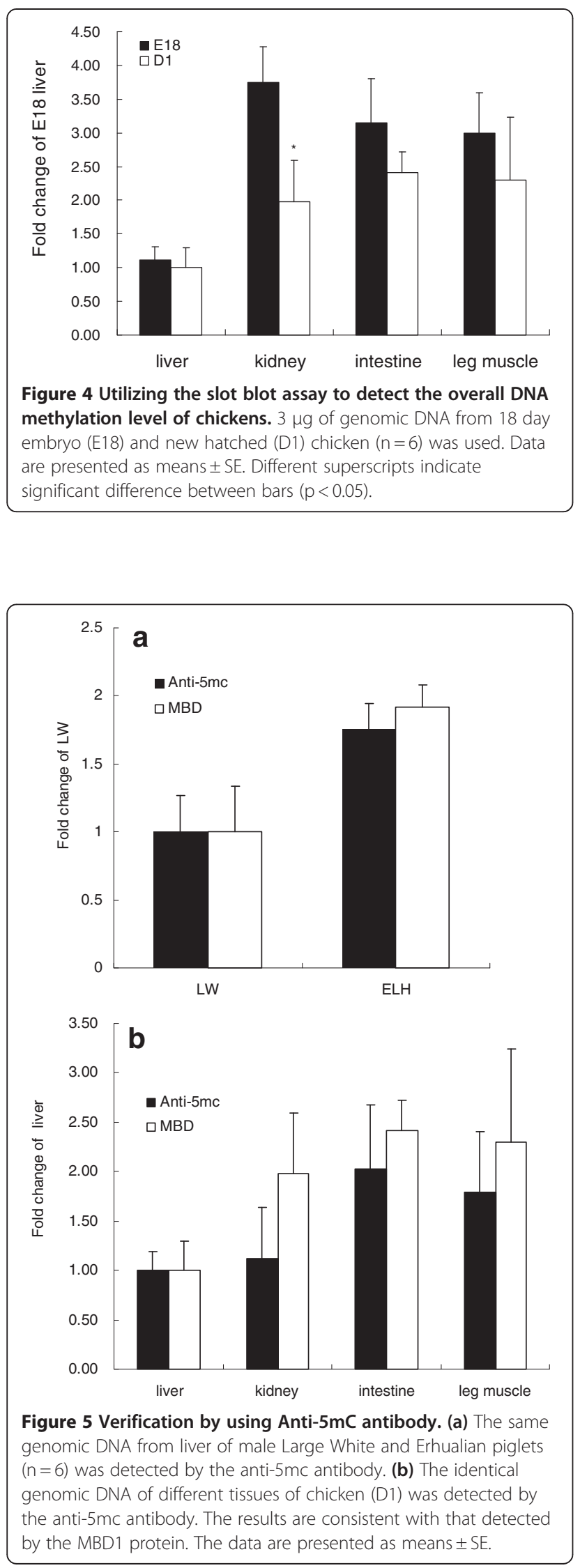

other Southwestern immunoblotting assays with anti-5methylcytosine antibody [24]. Although the sensitivity of the slot blot using MBD1 protein is relatively lower compared to methods such as HPLC or HPEC [11], it would meet the needs of those studies in which an semiquantitative estimation is adequate and quantity of the DNA samples is not restricted.

Levels of methylated DNA are known to be tissue- and species-specific $[6,25,26]$, and change during development [27]. Analysis of the overall DNA methylation level revealed that in normal human tissue, the most highly methylated DNA was from thymus and the least was from sperm [28]. Gama-Sosa [26] analyzed the overall DNA methylation extent in rats, mice and four types of monkeys, and they demonstrated that there were some similarities among tissues in mammals that they examined. For example, brain and thymus DNA were hypermethylated compared to most other organ DNA. Our result showed that in pig, muscle had the highest methylation level compared to the liver and adrenal gland. The physiological significance of these marked differences in overall DNA methylation level among the organs of a given species is not yet clear. Several lines of evidence demonstrate that high levels of DNA methylation are associated with gene silencing [1]. However, no apparent correlation is observed in the tissue-specific differences in levels of human overall DNA methylation and the extent of transcriptional activity [28]. Variations in the overall DNA methylation level of a certain type of tissue might indicate, to some extent, the net change of the transcriptional activity of all the genes in all the cell types and thus, could be related to differentiation and function of these tissues [26]. Our results also indicate that the overall DNA methylation level in the liver of swine differs between breeds; other tissues showed the same tendency, but no significant change was observed.

Developmental changes in DNA methylation will be helpful to understand the molecular basis of age-related physiological and pathological changes [29]. It has been illustrated that the overall DNA methylation levels decrease with age in human and mouse [30]. All the chicken tissues detected in the present study showed a decrease from E18 to D1. The reduction of the overall DNA level is a net effect of increases and decreases in methylation that occur across the whole genome [31]. The age-related decrease of methylation in CpG islands seems uncommon [32], whereas the age-related demethylation of repetitive sequence was common in human and other animals [33-35]. However, illustration of DNA methylation changes with age at specific loci is far from complete, and beyond the scope of our present study. In our study, the kidney showed a significant developmental change. Previous studies suggest that some organs, such as lung and kidney, underwent significant biochemical changes after birth 
[36-38]. Such biochemical changes are regulated by hormones [37] and may be related to the overall DNA methylation changes.

It is noted, however, that our assay is limited in offering the absolute values for the proportion of methylated cytosine, because fully methylated and unmethylated control DNA for swine and chicken are not available. However, an absolute percentage is not always necessary. For example, one research study aimed to analyze the relationship between an overgrowth phenotype of bovine fetuses and DNA methylation, and they compared the overall DNA methylation level of liver and placental cotyledon between the overgrowth groups and controls by using HPCE [39]. HPCE offered an absolute percentage of methylation, but actually a semi-quantitative analysis like our assay is adequate to serve the purpose.

The slot blot assay with MBD1 protein may also be useful for many different methylation detection applications that were not explored in this study. Its sensitivity, specificity and ease of use would allow for enhancing our understanding of the role of DNA methylation in different tissues of various species of animals under different situations.

\section{Methods}

\section{Ethical statement}

The slaughter and sampling procedures complied with the "Guidelines on Ethical Treatment of Experimental Animals" (2006) No. 398 set by the Ministry of Science and Technology, China and the Regulation regarding the Management and Treatment of Experimental Animals" (2008) No.45 set by the Jiangsu Provincial People's Government. The experiment was conducted following the guidelines of Animal Ethics Committee at Nanjing Agricultural University, China.

\section{DNA sample preparation}

Genomic DNA was extracted from tissues by incubation in lysis buffer (20 mM Tris (pH 8), $20 \mathrm{mM}$ EDTA, 2\% SDS and $0.5 \mathrm{mg} / \mathrm{ml}$ Proteinase $\mathrm{K}$ ) overnight at $55^{\circ} \mathrm{C}$ followed by phenol:chloroform extraction and ethanol precipitation. The extracted DNAs were quantified using the NanoDrop $^{\text {TM }} 1000$ Spectrophotometer (Thermo Scientific, USA). Each sample was diluted with distilled water into a final concentration of $100 \mathrm{ng} / \mu \mathrm{l}$.

\section{Preparation of $\lambda D N A$}

We methylated $1 \mu \mathrm{g}$ 入DNA (Promega D1521) with $4 \mathrm{U}$ of the CpG methyltransferase SssI in $20 \mu \mathrm{l}$ reaction volumes with $1 \times$ NEBuffer 2 and $160 \mu \mathrm{mol} / \mathrm{l} \mathrm{S}$ adenosylemthyionine for $2 \mathrm{~h}$ at $37^{\circ} \mathrm{C}$ (all reagents from New England Biolabs). To confirm the complete methylation, both the native double-stranded mockand M.SssI-methylated XDNA were digested by Hin$d$ III, and then they were subjected to restriction analysis using the methylation sensitive enzyme HpaII (all the enzymes from New England Biolabs) on 1\% agarose gel.

Methylated $\lambda$ DNA (100\%) was diluted with unmethylated $\lambda \mathrm{DNA}(0 \%)$ to create a dilution series of $100 \%, 80 \%$, $60 \%, 40 \%, 20 \%, 0 \%$ in a total amounts of $500 \mathrm{ng}$. We then used duplicate DNA dilutions to do the slot blot. One membrane was measured the methylation percentage as described, and the other was immersed in methylene blue stain for $5 \mathrm{~min}$ at room temperature and wash the membrane three times with water.

\section{Recombinant protein}

Prof. Adrian P. Bird at the Welcome Trust Centre for Cell Biology University of Edinburgh, UK kindly donated the plasmid of $1 \times \mathrm{MBD}(\mathrm{pET}-1 \times \mathrm{MBD})$. We transformed the plasmids to BL21 (DE3). Two hundreds mls BL21 (DE3) cultures were induced by $1 \mathrm{mM}$ IPTG and the recombinant His6-tagged MBD1 proteins were prepared by denaturationrenaturation procedure as previously described [20,21].

\section{Slot blot assay}

The slot blot apparatus (Cleaver Model, 48 slots) was assembled using Whatman $3 \mathrm{MM}$ filter and a pre-wetted nitrocellulose membrane, and it was connected to a vacuum pump. For slot blotting, $40 \mu \mathrm{l}$ of DNA samples at the concentration of $100 \mathrm{ng} / \mu \mathrm{l}$ were taken and brought up to $200 \mathrm{ml}$ with water, the unused slots were filled with $200 \mathrm{ml}$ distilled water, and then drawn by vacuum and immobilized by heating at $80^{\circ} \mathrm{C}$ for one hour. The membrane was blocked for $2 \mathrm{~h}$ at room temperature in 5\% skim milk powder in Tris- $\mathrm{HCl}$ buffered saline containing Tween-20 (0.025 M Tris-HCl, $0.15 \mathrm{M} \mathrm{NaCl}, \mathrm{pH}$ 7.6, 0.05\% Tween-20, TBST). The membrane was then incubated with TBST buffer containing 5\% skim milk and $20 \mu \mathrm{g} / \mathrm{ml}$ purified recombinant MBD1 protein for $2 \mathrm{~h}$ at room temperature or, alternatively overnight at $4^{\circ} \mathrm{C}$. The membrane was washed three times with TBST. The bound protein was detected by incubation with HisProbe-HRP (Thermo Scientific, USA) working solution (1:5000 of stock in $2.5 \%$ BSA TBST) for $1 \mathrm{~h}$. Again, the membrane was washed three times with TBST and the blot was processed using the Supersignal West Dura Extended Duration Substrate (Thermo scientific, USA) according to the manufacturer's introductions. Chemiluminescence was detected with Versa Doc ${ }^{\mathrm{TM}}$ imaging system (BIO-RAD, USA) and intensity of each band on the slot was measured using the Quantity One Analysis Software (BIO-RAD, USA).

\section{Statistical analysis}

All data are presented as the mean \pm SEM. All statistical analyses were performed with two-way analysis of variance (ANOVA) using the general linear model (GLM) procedure of SPSS 17.0 for Windows, followed by post-hoc analysis 
using the S-N-K method. For single factor studies, comparison was performed with Student's $T$ test for independent samples. Differences were considered significant when $\mathrm{p}<0.05$.

\section{Conclusion}

In conclusion, the slot blot assay is a sensitive, highly specific and inexpensive method for semi-quantitative estimation of overall DNA methylation. This assay does not require sophisticated equipments, or expensive technologies like sequencing, and also does not have the species specificity, thus providing a useful tool for the overall DNA methylation studies on domestic animals.

Competing interests

All the authors declare that they have no competing interests.

\section{Authors' contributions}

RZ designed the study. CZ carried out the experiment, participated in the design of the study and drafted the manuscript. RL performed the statistical analysis and helped to draft the manuscript. All authors read and approved the final manuscript.

\section{Acknowledgements}

This work was supported by the National Basic Research Program of China (2012CB124703), the NSFC-Guangdong Joint Fund (Project No. U0931004), the Major National Science \& Technology Projects of China (2009ZX08009138B), the Special Fund for Agro-scientific Research in the Public Interest (201003011) and the Priority Academic Program Development of Jiangsu Higher Education Institutions.

Received: 25 November 2011 Accepted: 18 April 2012

Published: 14 May 2012

\section{References}

1. Bird A: DNA methylation patterns and epigenetic memory. Genes Dev 2002, 16:6-21

2. Reik W, Dean W, Walter J: Epigenetic reprogramming in mammalian development. Science 2001, 293:1089-1093.

3. Rougier N, Bourc'his D, Gomes DM, Niveleau A, Plachot M, Paldi A, ViegasPequignot $\mathrm{E}$ : Chromosome methylation patterns during mammalian preimplantation development. Genes and development 1998, 12:2108-2113.

4. Li E, Beard C, Jaenisch R: Role for DNA methylation in genomic imprinting. Nature 1993, 366:362-365.

5. Walsh CP, Chaillet JR, Bestor TH: Transcription of IAP endogenous retroviruses is constrained by cytosine methylation. Nat Genet 1998, 20:116-117.

6. Pogribny I, Raiche J, Slovack M, Kovalchuk O: Dose-dependence, sex- and tissue-specificity, and persistence of radiation-induced genomic DNA methylation changes. Biochem Biophys Res Commun 2004, 320:1253-1261.

7. Xu N, Azziz R, Goodarzi MO: Epigenetics in polycystic ovary syndrome: a pilot study of global DNA methylation. Fertility and sterility 2010, 94: 781-783. e781.

8. Ehrlich M: DNA methylation in cancer: too much, but also too little. Oncogene 2002, 21:5400-5413.

9. Robertson KD: DNA methylation and human disease. Nat Rev Genet 2005 6:597-610.

10. Terry MB, Delgado-Cruzata L, Vin-Raviv N, Wu HC, Santella RM: DNA methylation in white blood cells: Association with risk factors in epidemiologic studies. Epigenetics 2011, 6:828-837.

11. Fraga MF, Esteller M: DNA methylation: a profile of methods and applications. BioTechniques 2002, 33:636-649. 632, 634.

12. Laird PW: Principles and challenges of genomewide DNA methylation analysis. Nat Rev Genet 2010, 11:191-203.

13. Nan X, Meehan RR, Bird A: Dissection of the methyl-CpG binding domain from the chromosomal protein MeCP2. Nucleic Acids Res 1993, 21:4886-4892.
14. Veenstra GJC, Bogdanovic O: DNA methylation and methyl-CpG binding proteins: developmental requirements and function. Chromosoma 2009, 118:549-565.

15. Hendrich B, Bird A: Identification and characterization of a family of mammalian methyl-CpG binding proteins. Mol Cell Biol 1998, 18:6538-6547.

16. Fujita N, Shimotake N, Ohki I, Chiba T, Saya H, Shirakawa M, Nakao M: Mechanism of transcriptional regulation by methyl-CpG binding protein MBD1. Mol Cell Biol 2000, 20:5107-5118.

17. Nair SS, Coolen MW, Stirzaker C, Song JZ, Statham AL, Strbenac D, Robinson MW, Clark SJ: Comparison of methyl-DNA immunoprecipitation (MeDIP) and methyl-CpG binding domain (MBD) protein capture for genomewide DNA methylation analysis reveal CPG sequence coverage bias. Epigenetics 2011, 6:34-44

18. Clouaire T, de Las Heras Jl, Merusi C, Stancheva I: Recruitment of MBD1 to target genes requires sequence-specific interaction of the MBD domain with methylated DNA. Nucleic Acids Res 2010, 38:4620-4634.

19. Rauch TA, Pfeifer GP: DNA methylation profiling using the methylatedCpG island recovery assay (MIRA). Methods 2010, 52:213-217.

20. Jorgensen HF, Adie K, Chaubert P, Bird AP: Engineering a high-affinity methyl-CpG-binding protein. Nucleic Acids Res 2006, 34:e96.

21. Cipriany BR, Zhao R, Murphy PJ, Levy SL, Tan CP, Craighead HG, Soloway PD: Single molecule epigenetic analysis in a nanofluidic channel. Anal Chem 2010, 82:2480-2487.

22. Li M, Hu SL, Shen ZJ, He XD, Tao SN, Dong L, Zhu YY: High-performance capillary electrophoretic method for the quantification of global DNA methylation: application to methotrexate-resistant cells. Anal Biochem 2009, 387:71-75.

23. Stach D, Schmitz OJ, Stilgenbauer S, Benner A, Dohner H, Wiessler M, Lyko F: Capillary electrophoretic analysis of genomic DNA methylation levels. Nucleic Acids Res 2003, 31:E2.

24. Oakeley EJ, Podesta A, Jost JP: Developmental changes in DNA methylation of the two tobacco pollen nuclei during maturation. Proc Natl Acad Sci USA 1997, 94:11721-11725.

25. Gonzalgo ML, Jones PA: Mutagenic and epigenetic effects of DNA methylation. Mutat Res 1997, 386:107-118.

26. Gama-Sosa MA, Midgett RM, Slagel VA, Githens S, Kuo KC, Gehrke CW, Ehrlich M: Tissue-specific differences in DNA methylation in various mammals. Biochim Biophys Acta 1983, 740:212-219.

27. Thompson RF, Atzmon G, Gheorghe C, Liang HQ, Lowes C, Greally JM, Barzilai N: Tissue-specific dysregulation of DNA methylation in aging. Aging Cell 2010, 9:506-518.

28. Ehrlich M, Gama-Sosa MA, Huang LH, Midgett RM, Kuo KC, McCune RA, Gehrke C: Amount and distribution of 5-methylcytosine in human DNA from different types of tissues of cells. Nucleic Acids Res 1982, 10:2709-2721.

29. Petronis A: Human morbid genetics revisited: relevance of epigenetics. Trends in genetics: TIG 2001, 17:142-146.

30. Fuke C, Shimabukuro M, Petronis A, Sugimoto J, Oda T, Miura K, Miyazaki T, Ogura C, Okazaki Y, Jinno Y: Age related changes in 5-methylcytosine content in human peripheral leukocytes and placentas: an HPLC-based study. Ann Hum Genet 2004, 68:196-204.

31. Dunn BK: Hypomethylation: one side of a larger picture. Ann N Y Acad Sci 2003, 983:28-42.

32. Tra J, Kondo T, Lu Q, Kuick R, Hanash S, Richardson B: Infrequent occurrence of age-dependent changes in CpG island methylation as detected by restriction landmark genome scanning. Mech Ageing Dev 2002, 123:1487-1503.

33. Hornsby PJ, Yang L, Gunter LE: Demethylation of satellite I DNA during senescence of bovine adrenocortical cells in culture. Mutat Res 1992, 275:13-19.

34. Suzuki T, Fujii M, Ayusawa D: Demethylation of classical satellite 2 and 3 DNA with chromosomal instability in senescent human fibroblasts. Exp Gerontol 2002, 37:1005-1014.

35. Howlett D, Dalrymple S, Mays-Hoopes LL: Age-related demethylation of mouse satellite DNA is easily detectable by HPLC but not by restriction endonucleases. Mutat Res 1989, 219:101-106.

36. Powell JT, Whitney PL: Postnatal development of rat lung. Changes in lung lectin, elastin, acetylcholinesterase and other enzymes. The Biochemical journal 1980, 188:1-8.

37. Imamura $Y$, Iwamoto $K$, Yanachi $Y$, Higuchi T, Otagiri M: Postnatal development, sex-related difference and hormonal regulation of acetohexamide reductase activities in rat liver and kidney. J Pharmacol Exp Ther 1993, 264:166-171. 
38. Neiss WF, Klehn KL: The postnatal development of the rat kidney, with special reference to the chemodifferentiation of the proximal tubule. Histochemistry 1981, 73:251-268.

39. Hiendleder S, Mund C, Reichenbach HD, Wenigerkind H, Brem G, Zakhartchenko V, Lyko F, Wolf E: Tissue-specific elevated genomic cytosine methylation levels are associated with an overgrowth phenotype of bovine fetuses derived by in vitro techniques. Biol Reprod 2004, 71:217-223.

doi:10.1186/1756-0500-5-234

Cite this article as: Zhang et al:: A semi-quantitative assay of overall

DNA methylation status using Methyl-CpG binding protein (MBD1). BMC

Research Notes 2012 5:234.

\section{Submit your next manuscript to BioMed Central and take full advantage of:}

- Convenient online submission

- Thorough peer review

- No space constraints or color figure charges

- Immediate publication on acceptance

- Inclusion in PubMed, CAS, Scopus and Google Scholar

- Research which is freely available for redistribution 